\title{
Lack of Pattern Separation in Sensory Inputs to the Olfactory Bulb during Perceptual Learning
}

\author{
Monica W. Chu, Wankun L. Li, and (DTakaki Komiyama
}

DOI:http://dx.doi.org/10.1523/ENEURO.0287-17.2017

Neurobiology Section, Center for Neural Circuits and Behavior, and Department of Neurosciences, University of California, San Diego, La Jolla, CA 92093

\begin{abstract}
Recent studies revealed changes in odor representations in the olfactory bulb during active olfactory learning (Chu et al., 2016; Yamada et al., 2017). Specifically, mitral cell ensemble responses to very similar odorant mixtures sparsened and became more distinguishable as mice learned to discriminate the odorants over days (Chu et al., 2016). In this study, we explored whether changes in the sensory inputs to the bulb underlie the observed changes in mitral cell responses. Using two-photon calcium imaging to monitor the odor responses of the olfactory sensory neuron (OSN) axon terminals in the glomeruli of the olfactory bulb during a discrimination task, we found that OSN inputs to the bulb are stable during discrimination learning. During one week of training to discriminate between very similar odorant mixtures in a Go/No-go task, OSN responses did not show significant sparsening, and the responses to the trained similar odorants did not diverge throughout training. These results suggest that the adaptive changes of mitral cell responses during perceptual learning are ensured by mechanisms downstream of OSN input, possibly in local circuits within olfactory bulb.
\end{abstract}

Key words: mitral cells; olfactory bulb; olfactory sensory neurons; perceptual learning; plasticity; two-photon imaging

\section{Significance Statement}

Odor representations in the rodent olfactory bulb have been demonstrated to undergo dynamic changes during a variety of olfactory experiences. In particular, odor representations in mitral cells, the primary projection neurons of the olfactory bulb, become more different (pattern separation) when mice are trained to distinguish between two similar odor mixtures. Here, we address whether similar changes occur in olfactory sensory neurons (OSNs), which provide input onto mitral cells. We find that OSN odor representations do not exhibit pattern separation when mice are trained to discriminate between two similar odor mixtures, suggesting that the changes likely occur downstream of OSNs during this task.

\section{Introduction}

Olfactory transduction occurs when odorants bind to specific receptors expressed by olfactory sensory neurons (OSNs), each of which expresses only one of $\sim 1000$ types of odorant receptors in the nasal epithelium (Ressler

Received August 8, 2017; accepted September 11, 2017; First published September 21, 2017.

The authors declare no competing financial interests.

Author contributions: T.K. designed research; M.W.C., W.L.L., and T.K. performed research; M.W.C. and T.K. analyzed data; M.W.C. and T.K. wrote the paper.

This work was supported by grants from National Institutes of Health (R01 NS091010A, R01 EY025349, R01 DC014690, P30 EY022589, and U01 NS094342), Pew Charitable Trusts, David \& Lucile Packard Foundation, McKnight Foundation, Human Frontier Science Program, and New York Stem Cell Foundation (T.K.).

Acknowledgements: We thank A. N. Kim, K. O'Neil, L. Hall, and T. Loveland et al., 1994; Vassar et al., 1994; Mombaerts et al., 1996). Axons from OSNs expressing the same type of receptor converge onto one or two glomeruli on the surface of the olfactory bulb; thus different odorants are represented at this early stage in olfactory encoding by unique combina-

for technical assistance; the GENIE Project at Janelia Research Campus for GCaMP6f; and members of the Komiyama lab for comments and discussions.

Correspondence should be addressed to Takaki Komiyama, 9500 Gilman Drive MC0634, Center for Neural Circuits and Behavior, Room 304, La Jolla, CA 92093, E-mail: tkomiyama@ucsd.edu.

DOI:http://dx.doi.org/10.1523/ENEURO.0287-17.2017

Copyright (C) 2017 Chu et al.

This is an open-access article distributed under the terms of the Creative Commons Attribution 4.0 International license, which permits unrestricted use, distribution and reproduction in any medium provided that the original work is properly attributed. 
tions of activated glomeruli. At the glomerular layer, OSNs provide input onto mitral/tufted cells, the primary projection neurons of the olfactory bulb, which in turn send their axons to higher brain areas (Price and Powell, 1970). Additionally, throughout the olfactory bulb, inhibitory interneurons play a major role in transforming odor representations (Lledo et al., 2008; Mcgann, 2013; Imai, 2014; Yu et al., 2014).

Odor representations in the early olfactory system are highly dynamic and have been shown to be modulated by various types of olfactory experience. For example, the activity of OSNs can change with passive experience (Kass et al., 2016) or associative learning, such as fear conditioning (Kass et al., 2013) or odor-reward association (Abraham et al., 2014). Experience has also been shown to induce response changes further downstream in the olfactory circuit: changes in odor responses in inhibitory interneurons of the olfactory bulb, which are targets of feedback from cortical and neuromodulatory areas (Ma and Luo, 2012; Nunez-Parra et al., 2013; Boyd et al., 2015; Otazu et al., 2015), have been shown to correlate with odor-specific changes in behavior (Mandairon et al., 2008; Moreno et al., 2009). Additionally, mitral cell activity can also be modulated by passive experience or behavioral training (Kay and Laurent, 1999; Doucette and Restrepo, 2008; Doucette et al., 2011; Kato et al., 2012; Li et al., 2015; Yamada et al., 2017).

In particular, we recently showed that mitral cell odor ensembles undergo bidirectional changes in odor representations during week-long discrimination learning. Specifically, when mice learned to discriminate between very different odorants, the representations of the odorants became more similar to each other. In contrast, discrimination learning of very similar odorants led to an enhanced separation of the odor representations, correlating with the improved ability of mice to discriminate the similar odorants (Chu et al., 2016). These mitral cell response changes could arise from at least two different mechanisms. First, mitral cells may simply reflect the changes that occur at the level of OSN inputs. Second, plasticity downstream of OSN inputs may alter the way mitral cells respond to the same OSN inputs. To begin to distinguish these possibilities, here, we addressed whether OSN inputs show plasticity during the same paradigm in which mice learn to discriminate between very similar odorant mixtures. This was achieved by longitudinal two-photon calcium imaging to characterize the activity of OSN axon terminals in behaving mice. We find that although mice exhibited a behavioral improvement in their ability to discriminate between odorants during training, OSN odor representations remained relatively stable throughout training without exhibiting enhanced pattern separation, suggesting that learning-related plasticity likely occurs downstream of OSNs.

\section{Materials and Methods}

\section{Animals}

All procedures were in accordance with protocols approved by the UCSD Institutional Animal care and Use Committee and guidelines of the National Institutes of Health.
Transgenic mice were obtained from Jackson laboratories [OMP-tTA, RRID:IMSR_JAX:017754 (Yu et al., 2004) and tetO-GCaMP6s, RRID:IMSR_JAX:024742 (Wekselblatt et al., 2016)] and group housed in disposable plastic cages with corncob bedding in a reversed light cycle room (12/12 h). Experiments were all performed during the dark period.

\section{Surgeries}

Surgeries were performed in adult male mice (at least six weeks old) as described previously (Kato et al., 2012). Briefly, mice were anesthetized with isoflurane, the skull was exposed and a steel headplate was glued to the skull. The skull above the olfactory bulb was then removed and replaced with an optical glass window $(\sim 1 \times \sim 2 \mathrm{~mm})$, which was secured in place with dental cement. Mice were then allowed to recover for at least two weeks (35 \pm $9.3 \mathrm{~d}$, mean \pm SEM) before imaging.

\section{Odorant delivery}

Odorants (Sigma) were delivered to the mouse through a Teflon-coated tube at a final concentration of $100 \mathrm{ppm}$ and flow rate of $1 \mathrm{l} / \mathrm{min}$. Odorant vials contained odorant diluted in mineral oil (Thermo Fisher) to a calculated vapor pressure of $200 \mathrm{ppm}$, and a custom olfactometer mixed odorant vapor from odorant vials with filtered and humidified house air at 1:1 to achieve a final concentration of $100 \mathrm{ppm}$.

\section{Behavioral training}

The training protocol, including the duration, criteria and odorant choice, was identical to our previous study (Chu et al., 2016). Mice began water restriction ( $1 \mathrm{ml} / \mathrm{d})$ $\sim 3-5 \mathrm{~d}$ after surgery, and weight was maintained at $80-$ $85 \%$ of initial weight. Mice first went through a pretraining period, where they became accustomed to being headfixed in the imaging environment and learned the Go/ No-Go olfactory discrimination task.

The behavioral task was controlled by a real-time program (C. Brody). In the olfactory discrimination task, mice performed daily sessions that lasted 150 trials, or until the mouse disengaged, whichever came first. Mice performed $140.0 \pm 2.13$ trials $/ d$ (mean \pm SEM). In each trial, one of two odorants was pseudorandomly delivered (maximum of three trials in a row with the same odorant). Each trial consisted of a 4-s odorant delivery period, followed by a 2-s answer period, during which the mouse could choose whether or not to lick a lickport. A water reward ( $\sim 6 \mu$ l water) was delivered from the lickport if the rewarded odorant $(\mathrm{S}+)$ was delivered in a trial and the mouse responded by licking the lickport during the answer period. Any other action, such as not licking to $S+$ or the unrewarded odorant (S-), or licking to S-, did not result in a water reward. A 15-s intertrial interval followed the answer period, and there was no punishment delivered for error trials (not licking to $\mathrm{S}+$, or licking to $\mathrm{S}$-).

In the first phase of training, called pretraining ( $\sim 7-14$ d), mice were trained with citral $(S+)$ and limonene (S-). The intertrial interval (ITI) started at $3 \mathrm{~s}$ and as mice performed above $80 \%$ success rate, the ITI was increased incrementally by $2 \mathrm{~s}$ every half-session until the ITI reached $15 \mathrm{~s}$. Once the mice performed above $80 \%$ success rate for the first odorant pair (citral/limonene), they were trained with 
a second pair, +-carvone $(\mathrm{S}+)$ and cumene $(\mathrm{S}-)$ until they reached above an $80 \%$ success rate.

Pretraining was followed by the week-long difficult discrimination task, during which glomerular activity was imaged while mice were performing the same Go/No-Go task with a novel set of similar binary odorant mixtures consisting of heptanal (Sigma, W254002) and ethyl tiglate (Sigma, W246000). S+ was a mixture of $52 \%$ heptanal $48 \%$ ethyl tiglate, while S- was a mixture of $48 \%$ heptanal $52 \%$ ethyl tiglate.

\section{Imaging}

Two-photon imaging was performed with a commercial microscope (B-scope, Thorlabs) with $925 \mathrm{~nm}$ excitation from a Ti-Sa laser (Spectra-physics). Images were acquired at a framerate of $\sim 28 \mathrm{~Hz}$. Each imaging frame consisted of $512 \times 512$ pixels, and spanned $1132 \times 982$ $\mu \mathrm{m}$. Images were acquired for $\sim 2.4$-min-long segments, with intersegment intervals of $7 \mathrm{~s}$. Trials with missing data (trials which overlapped with the intersegment intervals) were not analyzed. A custom (MATLAB, RRID: SCR_001622) program performed motion correction (Fullframe cross-correlation correction) on imaging frames.

\section{Data analysis}

In two sessions, we were not able to collect imaging data, and these sessions were excluded from analysis (day 3: one mouse; day 6: one mouse).

\section{Regions of interest (RO/s)}

ROIs were manually drawn around individual glomeruli, using a reference image which was created from a maximum projection of the imaged data on the first day of the experiment. For subsequent days, ROls were shifted manually to accommodate shifts in alignment from day to day. All fluorescence pixel values within each ROI were averaged to create a fluorescence time series. For each trial, the time series for a single glomerulus was normalized to the baseline period for that trial (the $5 \mathrm{~s}$ preceding odor onset) to calculate the dF/F. The total number of animals imaged was 13 mice, and $32 \pm 2.38$ (mean \pm SEM) glomeruli were imaged in each mouse.

\section{Classifying glomeruli as divergent}

A glomerulus was divergent if the following criteria were met. Criterion 1: $\mathrm{dF} / \mathrm{F}$ is significantly different $(p<0.05)$ between odorant trials for $>75 \%$ of time points within a sliding half-second window during the odorant period. A Wilcoxon rank sum test was performed to compare odorant 1 and odorant $2 \mathrm{dF} / \mathrm{F}$ values for each time frame. Criterion 2: the difference between trial-averaged $\mathrm{dF} / \mathrm{F}$ trace for odorant 1 and odorant 2 exceed 0.2 in at least one time point during the sliding half-second window which meets the first criterion.

\section{Classifying glomeruli as responsive}

A glomerulus was classified as responsive if it was classified as divergent, and/or if the following criteria were met. Criterion 1: $\mathrm{dF} / \mathrm{F}$ is significantly different $(p<0.05)$ for $>75 \%$ of time points within a sliding half-second window during the odorant period. A Wilcoxon rank sum test was performed to compare all baseline values $(0-5 \mathrm{~s}$ of all trials) dF/F values with each time frame during the odor response period. Criterion 2: the difference between trial-averaged $\mathrm{dF} / \mathrm{F}$ trace for odorant 1 and odorant 2 exceed 0.2 in at least one time point during the sliding half-second window which meets the first criterion.

\section{Calculating d-prime}

All trial traces were smoothed with the MATLAB "smooth" function with a time constant of six frames $(\sim 0.25 \mathrm{~s})$. The sensitivity index d-prime was calculated for divergent glomeruli: d' $=\mid$ mean $d F / F_{\text {odorant } 1}-$ mean $d F / F_{\text {odorant } 2} \mid$ / pooled standard deviation odorant 1 and 2 . .

If a glomerulus was divergent on a given day, d' was calculated for each time frame during the odorant period (0-4 s after odorant onset). The maximum d' value of all frames during the odorant period was assigned to each glomerulus, and the average of these maximum d'values of divergent neurons for each mouse on each session was calculated and plotted in Figure $3 A$.

\section{Glomerular activity vectors}

For each mouse, decoder analysis was performed using 100 iterations. For each iteration, 14 glomeruli were randomly selected from all glomeruli that were responsive to at least one odorant in at least $1 \mathrm{~d}$. The subset size of $n=14$ glomeruli was determined by the mouse with the lowest number of responsive glomeruli.

For each trial, an activity vector was assembled by concatenating the average $\mathrm{dF} / \mathrm{F}$ from $0-2 \mathrm{~s}$ and 2-4 $\mathrm{s}$ bins during the odor period. A single mouse would then have a 28 -dimensional activity vector (14 glomeruli $\times$ two time bins per glomeruli).

Nearest-centroid decoder

The decoder accuracy was calculated as follows. Each trial was classified by assigning that trial with the identity of the odor with the closest centroid in glomerular activity space. The trial that was being classified was excluded from the odor centroid calculation. The decoder accuracy for each iteration for each day is then calculated as fraction of trials that were successfully classified by the decoder. The final decoder accuracy value is calculated as the mean of the 100 iterations.

\section{Correlation coefficient}

For each day and odor, a mean odor activity vector was created by averaging across trials for each odorant. The correlation coefficient between the means of the population activity vectors was calculated using the Matlab function "corrcoef." The mean correlation coefficient value across animals is plotted in Figure $3 B$.

Peak amplitude of odorant response

For glomeruli that were classified as having excitatory odorant responses, the peak amplitude was calculated as the maximum $\mathrm{dF} / \mathrm{F}$ between a time window of $0-8 \mathrm{~s}$ after odorant onset (Fig. 3C,D).

\section{Results}

\section{Chronic imaging of OSN activity in behaving mice}

We recently showed that when mice are trained to discriminate between very similar odorants, mitral cell odor representations for the similar odorants become more separable (Chu et al., 2016). In the current study, we addressed whether OSN inputs to the olfactory bulb exhibit plasticity during the same task. More specifically, we 
A

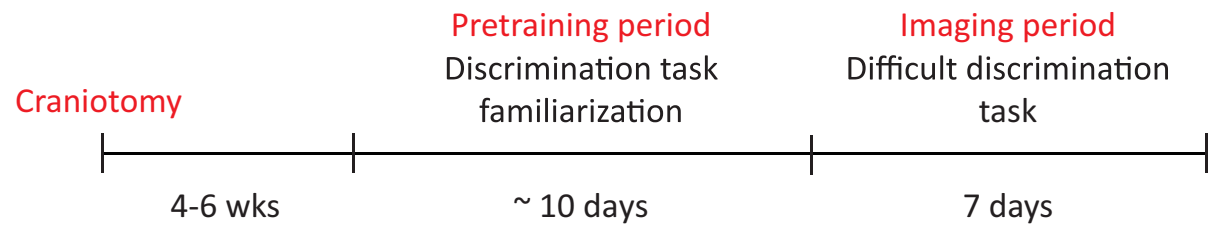

B

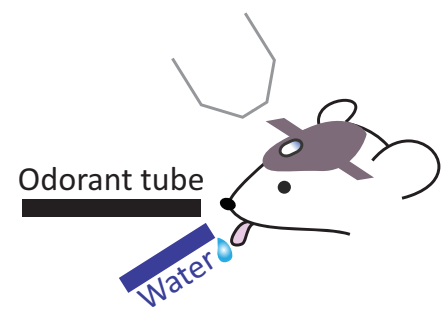

Odorant period Answer period Intertrial interval (4s)

(2s)

(15 s)

C
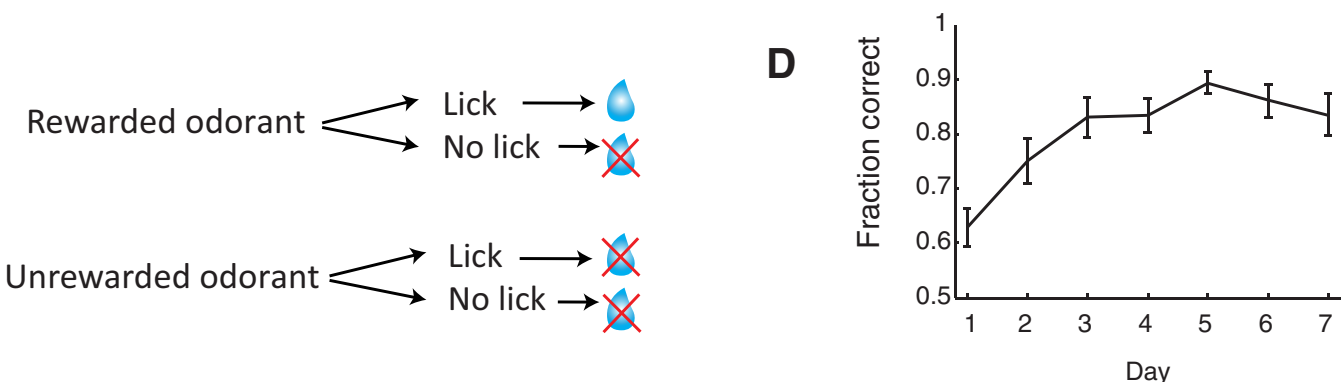

Figure 1. Training mice to perform a difficult discrimination task. $\boldsymbol{A}$, Experimental timeline. Water-restricted mice first undergo a pretraining period, where they become familiarized with the discrimination task using easy odorant pairs. After the pretraining period, glomerular responses are imaged while the mouse learns to perform a difficult discrimination task with two similar odor mixtures. $\boldsymbol{B}$, Schematic of imaging setup (left) and trial structure (right). $\boldsymbol{C}$, Schematic of behavioral paradigm. If a rewarded odorant is presented and the mouse responds with a lick, a water reward will be delivered through the lickport. If the unrewarded odor is delivered, no water reward will be given regardless of the mouse's actions. $\boldsymbol{D}$. Fraction of correctly answered trials (mean \pm SEM of all mice, $n=13$ mice) on each day of difficult discrimination training. Mice take $3 \mathrm{~d}$ on average to perform above an $80 \%$ success rate.

asked if training mice to discriminate between two similar odorants would enhance the separation of OSN responses to the two odorants. To record OSN activity, we used two-photon imaging of OSN axon terminals at the glomerular layer of the olfactory bulb in transgenic mice expressing GCaMP6s specifically in mature OSNs (OMPtTA::tetO-GCaMP6s). Craniotomies were performed above the right olfactory bulb, and after a recovery period, mice were trained to learn a Go/No-Go discrimination task (Fig. $1 A)$. First, mice underwent a pretraining period, where they learned the Go/No-Go paradigm in which mice were presented in each trial with one of two very different odorants, only one $(\mathrm{S}+)$ of which was paired with a water reward. Mice eventually learned to lick the lickport in response to $S+$ to obtain a water reward, while withholding from licking to the unrewarded odorant (S-; Fig. 1B,C). After reaching a success rate of above $80 \%$ correct in the Go/No-Go task with the pretraining odorants, mice were then trained to perform a difficult discrimination task in which they were required to discriminate between two highly similar binary odorant mixtures (odorant 1: S+, 52\% heptanal and $48 \%$ ethyl tiglate; odorant 2: S-, $48 \%$ heptanal and $52 \%$ ethyl tiglate; $\%$ are of total concentration of $100 \mathrm{ppm}$ ).

Throughout the week-long training in the difficult discrimination task, mice gradually improved their performance, taking on average $\sim 3 \mathrm{~d}(3.18 \pm 0.51$; mean \pm
SEM) to reach a level of expertise above an $80 \%$ success rate (Fig. 1D). The speed of learning was comparable to the same discrimination task in Chu et al., 2016 (Wilcoxon rank sum test, $p=0.15$ ) and require more days to reach expertise compared to the discrimination of very distinct odor pairs [also from Chu et al. (2016), Wilcoxon rank sum test, $p=0.0008$ ], indicating the requirement of perceptual learning in the difficult discrimination task.

\section{Glomerular odor responses do not sparsen during training}

To characterize OSN activity in behaving mice, we used two-photon calcium imaging to monitor the activity of OSN axon terminals in glomeruli throughout the learning of the difficult discrimination task (Fig. $2 A, B$ ). We tracked the activity in $32 \pm 2.4$ (mean \pm SEM) glomeruli in each mouse. Individual glomeruli exhibited odor responses by fluorescence changes during the 4-s odor period, with predominantly excitatory responses (Fig. 2C). With some exceptions, individual glomeruli showed stable odorant responses during difficult discrimination training (Fig. 2C). As a population, the fraction of responsive glomeruli was stable throughout training (Pearson correlation, $p=0.97$; Fig. $3 A$ ), and there was no change in the response amplitude of responsive glomeruli across days as a population (Kolmogorov-Smirnov test: odorant 1, $p=0.64$; odorant 
A

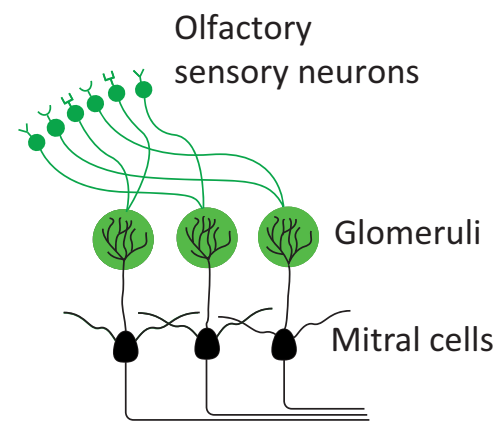

B

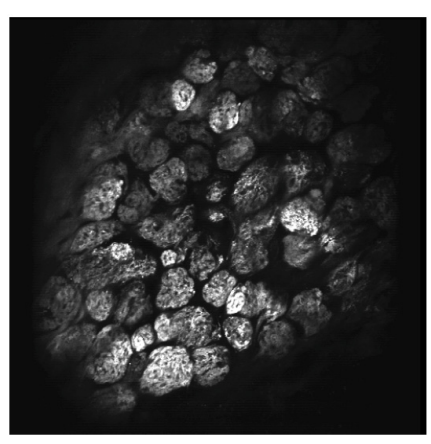

Day 7

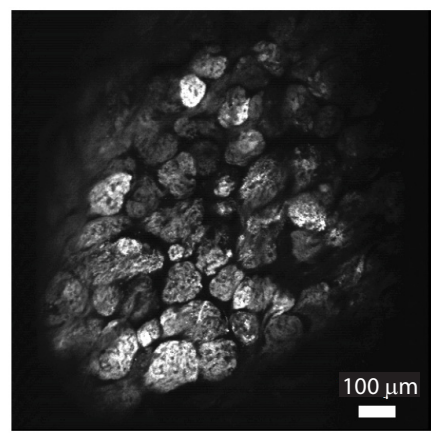

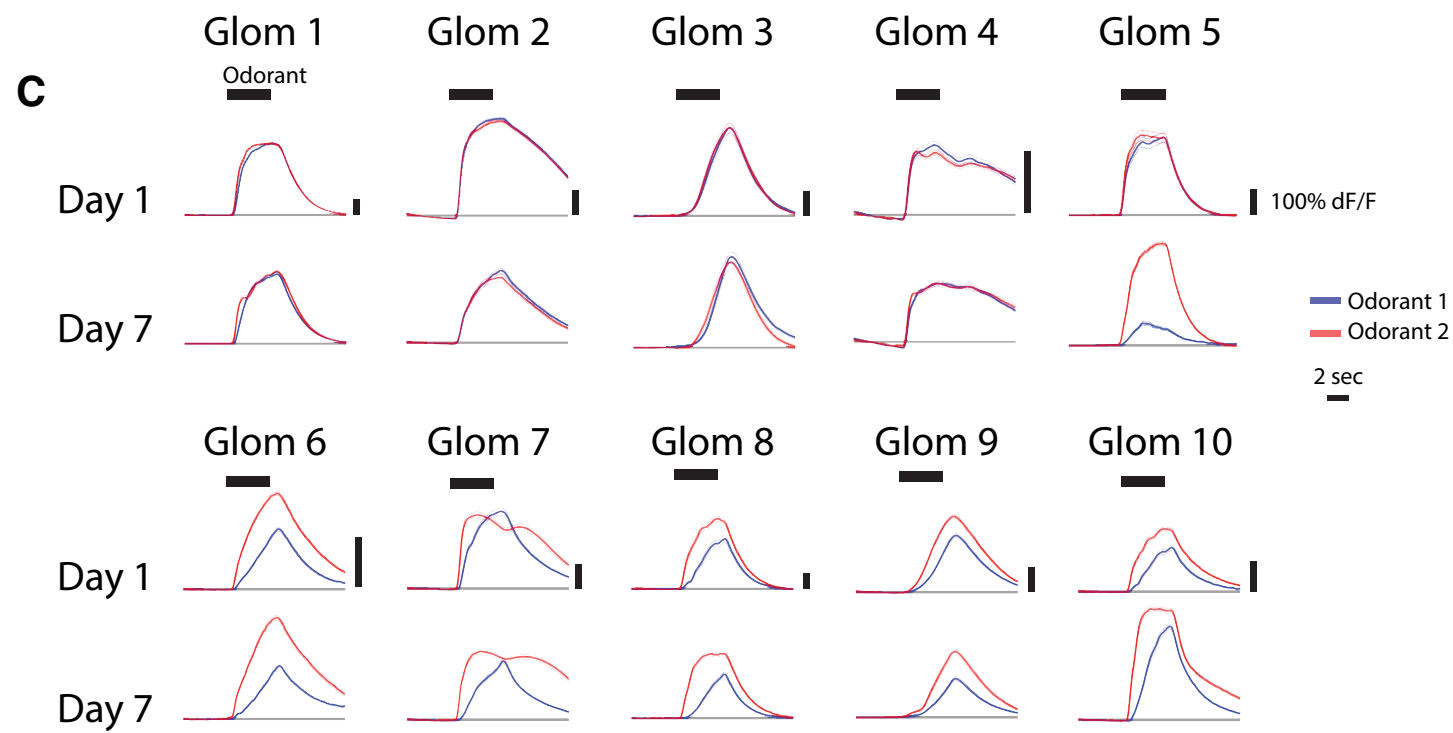

Figure 2. Imaging glomerular odor responses during training. $\boldsymbol{A}$, Schematic of the olfactory bulb. Two photon imaging of glomerular responses was performed in OMP-tTA::tetO-GCaMP6s mice, in which OSNs express GCaMP6s. B, An example of a typical glomerular field of view on the first day of imaging (day 1) and 6 d later (day 7). $\boldsymbol{C}$, Examples of odorant responses (mean \pm SEM) from individual glomeruli. Responses to the odorant 1 (S+, rewarded odorant) are shown in blue, and responses to odorant 2 (S-, unrewarded odorant) are shown in black. Odorant period is indicated by the thick horizontal black bar.

2. $p=0.99$; Fig. 3B). Additionally, the temporal dynamics of the glomerular odor responses remained stable for each odorant from day 1 to day 7 (Wilcoxon rank sum test for each imaging frame, false-discovery rate corrected: $q=0.05$, N.S.; Fig. 3C). This is reminiscent of the stable level of OSN odor responses observed during a weeklong passive exposure by imaging synaptopHlourin responses in OSN terminals (Kato et al., 2012) and in contrast to the profound sparsening observed in mitral cell responses over a week-long passive exposure (Kato et al., 2012) and discrimination learning (Chu et al., 2016). These results suggest that the sparsening of mitral cell responses during passive exposure and discrimination learning is likely due to changes downstream of OSN input onto mitral cells.

\section{No increase in separation of OSN odor responses during discrimination learning}

In addition to the sparsening, mitral cell responses to the similar odorants showed an enhanced separation during the discrimination task (Chu et al., 2016). We then asked whether OSN responses showed similar changes, potentially underlying the mitral cell changes and the behavioral improvement during learning. However, in contrast to what has been observed with mitral cell ensembles (Chu et al., 2016), there was no significant change in the fraction of glomeruli whose activity distinguished the two odorants ("divergent glomeruli") across days during training (Pearson correlation; divergent, $p=0.50$; divergent of responsive, $p=0.73$; Fig. $3 A$ ). Furthermore, in divergent glomeruli, the degree of divergence (quantified as d-prime) remained stable throughout training (Pearson correlation; $p=0.87$; Fig. $3 D$ ). Thus, we found no evidence for an enhanced separation of responses to the two similar odorants at the level of individual glomeruli.

Next, we investigated potential changes at the level of glomerular ensembles. To address this, we first calculated the correlation coefficient as a measure of similarity between glomerular ensemble response vectors. Consistent with what was observed in individual glomeruli, the correlation coefficient between glomerular odor responses was stable throughout training (Pearson correlation; $p=$ 
A
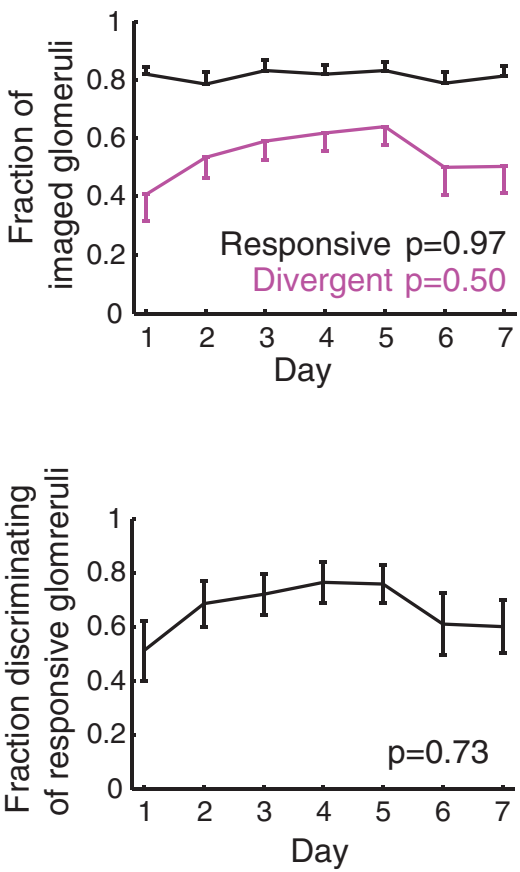

B
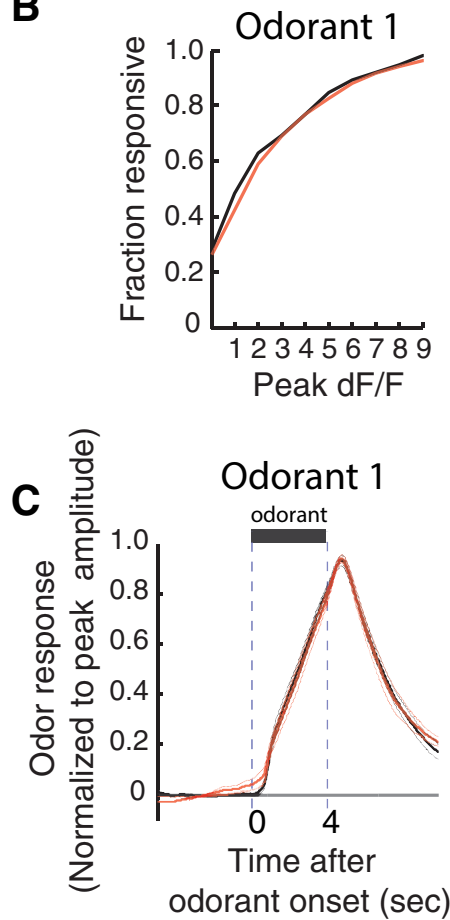

Odorant 2
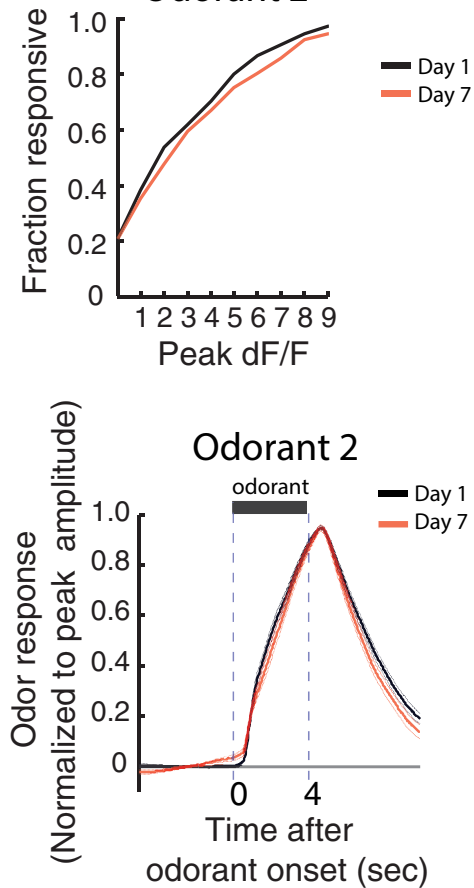

D

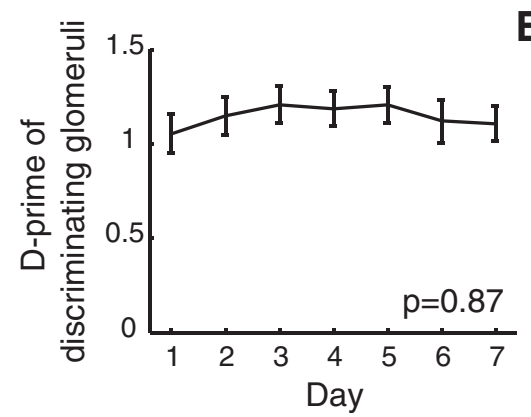

G

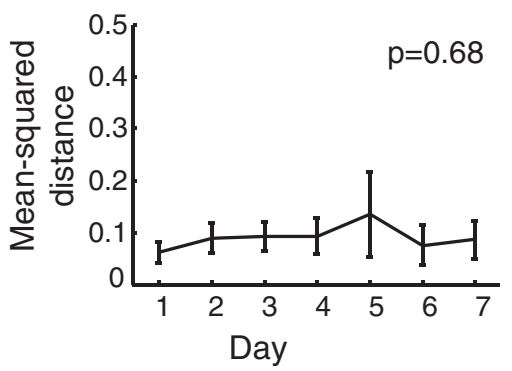

E

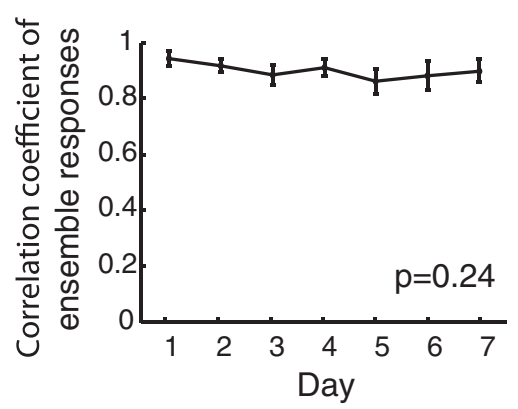

H

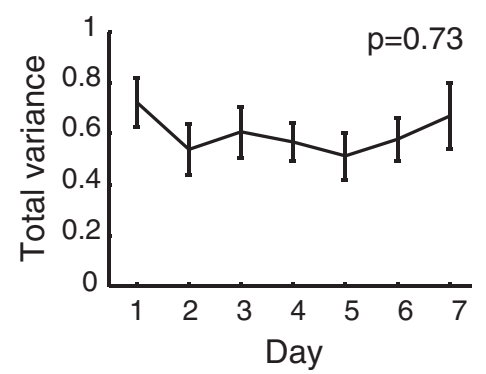

F

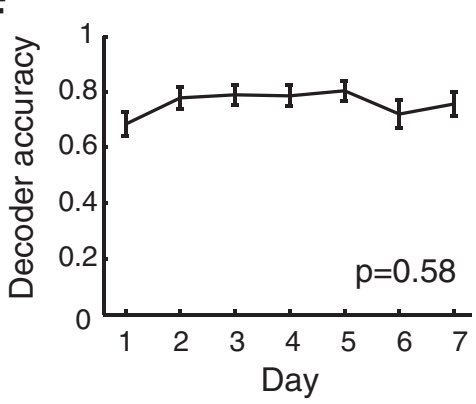

I

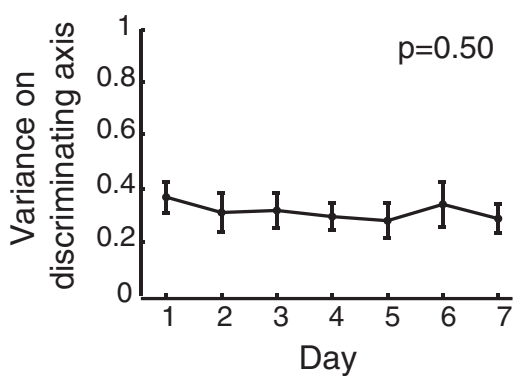

Figure 3. Glomerular odor representations do not show an increased separation during training. $\boldsymbol{A}$, top, Fractions of glomeruli classified as responsive (black) and divergent (magenta) are plotted for each day. The responsive fraction and divergent fraction remain stable across days (Pearson correlation; responsive, $p=0.97$; divergent, $p=0.50$ ). Bottom, Fraction of divergent glomeruli out of all responsive glomeruli does not significantly change during training (Pearson correlation; $p=0.73$ ). $\boldsymbol{B}$, Cumulative fraction distributions of the peak amplitude of excitatory glomerular odorant responses on day 1 and day 7 . There is no difference in the distributions for either odorant between day 1 and day 7 (Kolmogorov-Smirnov test: odorant 1, $p=0.64$; odorant 2, $p=0.99$ ). $\boldsymbol{C}$, Mean excitatory glomerular odorant responses on day 1 (black) and day 7 (red), normalized to peak amplitude. There are no significant differences between responses on day 1 and day 7 (Wilcoxon rank sum test for each imaging frame, false-discovery rate corrected: $q=0.05)$. $\boldsymbol{D}$, The averaged d-prime of all divergent glomeruli does not change with difficult discrimination training (Pearson correlation; $p=0.87$ ). $\boldsymbol{E}$, The correlation coefficient between averaged ensemble odorant responses does not change with difficult discrimination training (Pearson correlation; $p=0.24$ ). $\boldsymbol{F}$, The decoder accuracy does not change during difficult discrimination training (Pearson correlation; $p=0.58$ ). $\mathbf{G}-\mathbf{I}$, There were no significant changes in the $(\mathbf{G})$ mean-squared distance between odor 
continued

centroids nor $(\boldsymbol{H})$ the total variance across trials for each odor (Pearson correlation; mean-squared distance, $p=0.68$; total variance, $p=0.73)$. $\boldsymbol{I}$, There was also no change in the variance along the axis of discrimination (the axis containing the line connecting Odor 1 and Odor 2 centroids) for the decoder (Pearson correlation; $p=0.50$ ). Unless otherwise stated, mean \pm SEM are shown in line plots with error bars.

0.24; Fig. 3E). We next performed a linear decoder analysis to assess the discriminability between glomerular odor representations. The average decoder accuracy, or the fraction of correctly decoded trials on each day, remained stable during training (Pearson correlation; $p=$ 0.58; Fig. 3F). Consistent with the stable correlation coefficient and decoder accuracy, we found no change in the distance between the mean responses for the two odorants in glomerular activity space (Pearson correlation; $p=0.68$; Fig. $3 G$ ). We also did not observe any change in the total variance across same odor trials in glomerular activity space (Pearson correlation; $p=0.73$; Fig. $3 H$ ), nor in the variance along the decoder axis of discrimination (Pearson correlation; $p=0.50$; Fig. 3/). Thus, although mice exhibited a behavioral improvement in their ability to discriminate the two odorants during training, multiple measures of discriminability by glomerular ensembles indicate that OSN odor responses did not show an enhanced separation throughout training. Therefore, it seems unlikely that OSNs are a main source of the plasticity observed in mitral cell ensembles (Chu et al., 2016) during the learning of this difficult discrimination task.

\section{Discussion}

Recent studies have revealed changes in mitral cell responses during discrimination learning paradigms. In particular, the learning to discriminate between very similar odorants led to an enhanced pattern separation in mitral cell responses, potentially underlying the perceptual learning (Abraham et al., 2014; Chu et al., 2016). Here, we explored whether the mitral cell changes may be inherited from changes in OSN inputs to the bulb. However, the separation of odor responses of OSN inputs remained stable during the same week-long learning paradigm that induced an enhanced separation of mitral cell responses, suggesting that plasticity during this task occurs downstream of OSN input onto mitral cells.

We acknowledge that several previous studies have demonstrated changes in the glomerular activity during olfactory experiences. For example, week-long passive exposure to a single odorant resulted in a temporal divergence in OSN odorant responses (measured by the fluorescence of synaptopHluorin expressed in OSN axons) to a novel pair of similar odorants (Kass et al., 2016). Furthermore, fear conditioning has been demonstrated to result in the potentiation of the response to the paired odorant (Kass et al., 2013). Additionally, after odor-reward association learning, OSN responses to the trained odorants, which were monitored by intrinsic signal imaging, were shown to be potentiated (Abraham et al., 2014). We did not observe these changes in OSN activity. The source of this potential discrepancy is unclear and may be due to differences in behavioral contexts (including task difficulty and trial parameters), measurement methods (our GCaMP6s imaging vs synaptopHluorin signals or intrinsic signal imaging), choice of odorants used, etc. Nevertheless, in this and previous studies (Chu et al., 2016), we have compared the changes in OSN activity and mitral cell activity during the same behavioral task with the same odorants, providing a strong case for plasticity downstream of OSN inputs. We also note that our results do not exclude the potential contribution of changes in OSN activity that are not detected by our current method, such as changes in millisecond-level spike synchrony across OSNs, although it seems unlikely that such changes account for the entirety of the enhanced pattern separation observed in mitral cells.

There are many possible sites downstream of OSN input which could result in the changes in mitral cell activity during perceptual learning. For example, mitral cell activity is shaped by local inhibitory neurons, and plasticity in inhibitory connections could contribute to the enhanced pattern separation of mitral cell responses. Interestingly, thousands of newly generated inhibitory interneurons are integrated into the olfactory circuitry daily through adult neurogenesis, which provides an additional layer of inhibitory plasticity in the olfactory bulb (Alonso et al., 2006). Furthermore, the olfactory bulb receives ample feedback projections from higher brain centers. Cortical glutamatergic feedback, which mainly target inhibitory interneurons in the olfactory bulb, indirectly modulates mitral cell activity (Balu et al., 2007; Boyd et al., 2012; Markopoulos et al., 2012; Otazu et al., 2015; Mazo et al., 2016). Additionally, feedback from various neuromodulatory areas can shape mitral cell odor responses and have been demonstrated to play an important role in olfactory tasks such as odor discrimination and odor detection (Linster et al., 2001; Doucette and Restrepo, 2008; Chaudhury et al., 2009; Escanilla et al., 2010; Ma and Luo, 2012; Nunez-Parra et al., 2013; Kapoor et al., 2016). Future studies are needed to determine the specific loci and nature of changes responsible for the observed changes in mitral cell activity.

\section{References}

Abraham NM, Vincis R, Lagier S, Rodriguez I, Carleton A (2014) Long term functional plasticity of sensory inputs mediated by olfactory learning. Elife 3:e02109. CrossRef Medline

Alonso M, Viollet C, Gabellec MM, Meas-Yedid V, Olivo-Marin JC, Lledo PM (2006) Olfactory discrimination learning increases the survival of adult-born neurons in the olfactory bulb. $J$ Neurosci 26:10508-10513. CrossRef Medline

Balu R, Pressler RT, Strowbridge BW (2007) Multiple modes of synaptic excitation of olfactory bulb granule cells. J Neurosci 27:5621-5632. CrossRef 
Boyd AM, Sturgill JF, Poo C, Isaacson JS (2012) Cortical feedback control of olfactory bulb circuits. Neuron 76:1161-1174. CrossRef Medline

Boyd AM, Kato HK, Komiyama T, Isaacson JS (2015) Broadcasting of cortical activity to the olfactory bulb. Cell Rep 10:1032-1039. CrossRef Medline

Chaudhury D, Escanilla O, Linster C (2009) Bulbar acetylcholine enhances neural and perceptual odor discrimination. J Neurosci 29:52-60. CrossRef Medline

Chu MW, Li WL, Komiyama T (2016) Balancing the robustness and efficiency of odor representations during learning. Neuron 92:174186. CrossRef Medline

Doucette W, Restrepo D (2008) Profound context-dependent plasticity of mitral cell responses in olfactory bulb. PLoS Biol 6:e258. CrossRef

Doucette W, Gire DH, Whitesell J, Carmean V, Lucero MT, Restrepo $D$ (2011) Associative cortex features in the first olfactory brain relay station. Neuron 69:1176-1187. CrossRef Medline

Escanilla O, Arrellanos A, Karnow A, Ennis M, Linster C (2010) Noradrenergic modulation of behavioral odor detection and discrimination thresholds in the olfactory bulb. Eur $\mathrm{J}$ Neurosci 32: 458-468. CrossRef Medline

Imai T (2014) Construction of functional neuronal circuitry in the olfactory bulb. Semin Cell Dev Biol 35:180-188. CrossRef Medline

Kapoor V, Provost AC, Agarwal P, Murthy V (2016) Activation of raphe nuclei trigger rapid and distinct effects on parallel olfactory bulb output channels. Nat Neurosci 19:271-282. CrossRef

Kass MD, Rosenthal MC, Pottackal J, McGann JP (2013) Fear learning enhances neural responses to threat-predictive sensory stimuli. Science 342:1389-1392. CrossRef Medline

Kass MD, Guang SA, Moberly AH, McGann JP (2016) Changes in olfactory sensory neuron physiology and olfactory perceptual learning after odorant exposure in adult mice. Chem Senses 41: 123-133. CrossRef Medline

Kato HK, Chu MW, Isaacson JS, Komiyama T (2012) Dynamic sensory representations in the olfactory bulb: modulation by wakefulness and experience. Neuron 76:962-975. CrossRef Medline

Kay LM, Laurent G (1999) modulation of mitral cell activity in behaving rats. Nat Neurosci 2:1003-1009. CrossRef Medline

Li A, Gire DH, Restrepo D (2015) Spike-field coherence in a population of olfactory bulb neurons differentiates between odors irrespective of associated outcome. J Neurosci 35:5808-5822. CrossRef

Linster C, Garcia PA, Hasselmo ME, Baxter MG (2001) Selective loss of cholinergic neurons projecting to the olfactory system increases perceptual generalization between similar, but not dissimilar, odorants. Behav Neurosci 115:826-833. CrossRef

Lledo PM, Merkle FT, Alvarez-Buylla A (2008) Origin and function of olfactory bulb interneuron diversity. Trends Neurosci 31:392-400. CrossRef Medline

Ma M, Luo M (2012) Optogenetic activation of basal forebrain cholinergic neurons modulates neuronal excitability and sensory re- sponses in the main olfactory bulb. J Neurosci 32:10105-10116. CrossRef Medline

Mandairon N, Didier A, Linster C (2008) Odor enrichment increases interneurons responsiveness in spatially defined regions of the olfactory bulb correlated with perception. Neurobiol Learn Mem 90:178-184. CrossRef Medline

Markopoulos F, Rokni D, Gire DH, Murthy VN (2012) Functional properties of cortical feedback projections to the olfactory bulb. Neuron 76:1175-1188. CrossRef Medline

Mazo XC, Lepousez G, Nissant A, Valley MT, Lledo P (2016) GABA B receptors tune cortical feedback to the olfactory bulb. J Neurosci 36:8289-8304. CrossRef Medline

Mcgann JP (2013) Presynaptic inhibition of olfactory sensory neurons: new mechanisms and potential functions. Chem Senses 38:459-474. CrossRef Medline

Mombaerts P, Wang F, Dulac C, Chao SK, Nemes A, Mendelsohn M, Edmondson J, Axel R (1996) Visualizing an olfactory sensory map. Cell 87:675-686. Medline

Moreno MM, Linster C, Escanilla O, Sacquet J, Didier A, Mandairon N (2009) Olfactory perceptual learning requires adult neurogenesis. Proc Natl Acad Sci USA 106:17980-17985. CrossRef Medline

Nunez-Parra A, Maurer RK, Krahe K, Smith RS, Araneda RC (2013) Disruption of centrifugal inhibition to olfactory bulb granule cells impairs olfactory discrimination. Proc Natl Acad Sci USA 110: 14777-14782. CrossRef Medline

Otazu GH, Chae H, Davis MB, Albeanu DF (2015) Cortical feedback decorrelates olfactory bulb output in awake mice. Neuron 86: 1461-1477. CrossRef

Price JL, Powell TPS (1970) The mitral and short axon cells of the olfactory bulb. J Cell Sci 651:631-651. Medline

Ressler KJ, Sullivan SL, Buck LB (1994) Information coding in the olfactory system: evidence for a stereotyped and highly organized epitope map in the olfactory bulb. Cell 79:1245-1255. Medline

Vassar R, Chao SK, Sitcheran R, Nuñez M, Vosshall LB, Axel R (1994) Topographic organization of sensory projection to the olfactory bulb. Cell 79:981-991. Medline

Wekselblatt JB, Flister ED, Piscopo DM, Niell CM (2016) Largescale imaging of cortical dynamics during sensory perception and behavior. J Neurophysiol 115:2852-2866. CrossRef Medline

Yamada Y, Bhaukaurally K, Madarász TJ, Pouget A, Rodriguez I, Carleton A (2017) Context- and output layer-dependent long-term ensemble plasticity in a sensory circuit. Neuron 93:1198-1212.e5. CrossRef

Yu CR, Power J, Barnea G, Donnell SO, Brown HEV, Osborne J, Axe $R$, Gogos JA (2004) Spontaneous neural activity is required for the establishment and maintenance of the olfactory sensory map. Neuron 42:553-566. CrossRef

Yu Y, Migliore M, Hines ML, Shepherd GM (2014) Sparse coding and lateral inhibition arising from balanced and unbalanced dendrodendritic excitation and inhibition. J Neurosci 34:13701-13713. CrossRef Medline 